\title{
Habilidades Relevantes para a Perícia Contábil Criminal: a percepção dos Peritos e Delegados da Polícia Federal
}

\begin{abstract}
Resumo
A pesquisa buscou identificar quais são as habilidades consideradas mais relevantes para o exercício da perícia contábil criminal no País. Assim como em pesquisas internacionais, as habilidades percebidas como mais relevantes foram a comunicação escrita, a análise dedutiva e o pensamento crítico. Entre as habilidades menos relevantes, ficaram a entrevista e a resolução e negociação de conflitos. Na segunda parte, enquanto peritos e delegados, de forma conjunta, consideram que a comunicação escrita é a habilidade mais presente, os delegados divergem dos peritos em relação ao pensamento crítico e à serenidade. Adicionalmente, os respondentes indicaram habilidades que não estavam entre as investigadas, $\mathrm{e}$ as habilidades mais citadas foram a proatividade, a objetividade e a atualização. À luz da contabilidade forense, o método de pesquisa utilizado foi o survey, utilizando-se um questionário predefinido com questões abertas e fechadas, obtendo-se a participação de 144 respondentes. O estudo foi dividido em três partes: a primeira, sobre a percepção de relevância das habilidades, a segunda sobre a percepção da aplicação prática das habilidades e a terceira parte permitiu que os respondentes contribuíssem com sugestões de habilidades consideradas relevantes e que não constassem entre as investigadas. O estudo contribui para o estabelecimento de diretrizes curriculares de cursos de graduação e pós-graduação relacionados ao treinamento das habilidades consideradas como relevantes para formação de futuros profissionais, e para o aperfeiçoamento dos peritos criminais contábeis. Por fim, verifica-se que as habilidades investigadas e sugeridas têm o potencial de contribuir para todas as áreas da perícia contábil.
\end{abstract}

Palavras-chave: contabilidade forense; perícia contábil criminal; habilidades.
Carlos Roberto dos Santos Filho

Mestre em Contabilidade pela Fucape Business School, Perito Criminal Federal da Polícia Federal e Professor no Centro Universitário Tiradentes. Contato: Av. Walter Ananias, 705, Superintendência Regional de Polícia Federal em Alagoas, Jaraguá, Maceió/ AL, CEP: 57022-065

E-mail: prof.perito.carlosroberto@gmail.com

\section{Flávio Alves Carlos}

Mestre em Contabilidade pela Universidade Federal de Pernambuco, Perito Criminal Federal da Polícia Federal e Professor no Centro Universitário de Brasília. Contato: SAS Quadra 06, Lotes 09/10, Sala 909, Edifício-Sede do DPF, Asa Sul, Brasília/DF, CEP: 70256-180 E-mail: flaviocarlos.fac@gmail.com

\section{Fábio Moraes da Costa}

Doutor em Ciências Contábeis pela Universidade de São Paulo e Professor Associado da Fucape Business School. Contato: Av. Fernando Ferrari, 1358, Boa Vista, Vitória/ES, CEP: 29.075-505 E-mail:fabio@fucape.br 


\section{Introdução}

Em virtude dos escândalos envolvendo empresas e governos ao redor do mundo e também no Brasil, é natural que surjam providências no sentido de detectar e impedir fraudes, assim como para produção de provas. Para atender essa demanda, a profissão contábil vem passando por mudanças e chama a atenção sobre um novo mercado, com uma nova geração de contadores, os contadores forenses (Davis, Farrell \& Ogilby, 2010).

Alguns estudos propõem-se a discutir as competências, os conhecimentos e as habilidades técnicas que o contador forense deve possuir, para desempenhar, de maneira adequada, suas funções, bem como qual é o perfil desse profissional (Astutie \& Utami, 2013; Boys, 2008; Davis et al., 2010; Digabriele, 2008; Harris \& Brown, 2000). Considerando que um dos objetivos da contabilidade forense é identificar como os crimes são perpetrados, a expertise em relação aos princípios contábeis e normas de auditoria, sem domínio em identificar correlações entre tais regras e eventuais transações irregulares que afetem o patrimônio tanto de pessoas jurídicas como de pessoas físicas, revela na formação dos contadores uma tendência a menosprezar a importância do estudo relativo à prevenção e descoberta de fraudes, desfalques e de práticas contábeis inadequadas (Silva, 2012).

$\mathrm{Na}$ explicação da fraude, o contador forense pode contribuir ao entender quais são as condições gerais que possibilitaram sua ocorrência, trabalhando com o conceito de causa e efeito, facilitando a formulação de teses, teorias e suposições, até sua comprovação (Silva, 2012). Tendo em vista a discussão internacional acerca das habilidades necessárias ao contador forense (Digrabiele, 2008; Davis et al., 2010; Astutie \& Utami, 2013) e a similaridade dos objetivos de sua atuação com a do perito criminal federal contábil, cumpre investigar se essas habilidades são percebidas efetivamente como importantes, além disso, buscou-se aproveitar a experiência dos peritos e delegados da Polícia Federal para investigar qual é a percepção deles em relação à existência dessas habilidades na realização da perícia contábil criminal.

Sob o enfoque do combate à fraude na área criminal federal, o Departamento de Polícia Federal (DPF) possui um corpo técnico de peritos em investigação de fraude, os quais atuam na elucidação de diversos crimes contábeis e financeiros de grande repercussão nacional. Assim, surgiu a questão problema deste estudo: quais são as habilidades mais relevantes de um Perito Criminal Federal Contábil na percepção dos usuários e praticantes da perícia no Brasil? O objetivo desta pesquisa foi comparar a percepção dos peritos criminais federais e dos delegados da Polícia Federal em relação às habilidades mais relevantes esperadas de um perito criminal federal contábil à luz da contabilidade forense, assim como a percepção das habilidades no contexto atual de desenvolvimento de sua atividade.

A relevância deste estudo reside em dois pilares principais: o primeiro por se tratar de um estudo investigativo acerca da percepção dos profissionais que trabalham com a perícia contábil criminal federal no Brasil, sendo um grupo dos praticantes da perícia e outro dos usuários, trazendo, com isso, um retrato das habilidades consideradas importantes e as consideradas presentes na perícia contábil criminal federal, elemento essencial no processo de persecução penal; o segundo, por trabalhar um tema em ascensão e latente que é a contabilidade forense, cujas habilidades e definições indicam ser um pouco diferente do que é tratado como perícia contábil, sendo assim um assunto que ainda está florescendo no Brasil.

A pesquisa demonstrou que as habilidades de comunicação escrita, análise dedutiva e pensamento crítico são percebidas como mais relevantes pelos usuários e praticantes nacionais e estão em sintonia com pesquisas empíricas internacionais (Digrabiele, 2008). No entanto, a comparação da percepção, em relação às habilidades existentes, revelou convergências, como considerar a comunicação escrita e a análise dedutiva entre as mais presentes, e divergências entre os praticantes e usuários em relação às habilidades de conhecimento jurídico específico, serenidade, entrevista e resolução de problemas não estruturados.

Nesse cenário, os resultados contribuíram para o conhecimento das habilidades consideradas relevantes e o gap existente, de forma que se possa planejar as ações no sentido de melhorar a qualificação dos peritos criminais, bem como trouxe à discussão pelos usuários do sistema as características que precisam ser reavaliadas, inclusive na formação dos currículos de futuros contadores forenses pelas universidades em nível de graduação e pós-graduação. 


\section{Referencial Teórico}

A perícia contábil no Brasil constitui o conjunto de procedimentos técnico-científicos destinados a levar à instância decisória elementos de prova necessários a subsidiar a justa solução do litígio ou da constatação de fato, mediante laudo pericial contábil e/ou parecer técnico-contábil, em conformidade com as normas jurídicas e profissionais e com a legislação específica no que for pertinente (Conselho Federal de Contabilidade $[\mathrm{CFC}], 2015)$. Verifica-se uma abordagem ampla na definição da atuação da perícia contábil, pois se pode atuar nos ramos da justiça do Trabalho, Cível, Criminal, assim como área extrajudicial.

$\mathrm{Na}$ área internacional, a perícia contábil criminal é denominada pelo termo Forensic Accounting (Oliveira, 2002). A primeira pessoa a criar o nome Forensic Accounting, de forma impressa, foi provavelmente Maurice E. Peloubet, em 1946 (Crumbley, Heitger \& Smith, 2013). Forensic é definido como pertencente ao tribunal de justiça (Black, 1971). Contabilidade forense é a ação de identificar, registrar, liquidar, extrair, classificar, relatar e verificar dados financeiros passados ou outras atividades de contabilidade para resolução de disputas legais atuais ou potenciais, ou usar esses dados financeiros passados para projetar dados financeiros futuros para resolver disputas legais (Crumbley et al., 2013).

O termo fraude tem origem no latim "fraus" e indica ação praticada de má-fé, corresponde a um ato intencional ou omissão destinada a enganar pessoas físicas ou jurídicas, que resulta em perdas para a vítima e/ou ganhos para o fraudador (Silva, 2012). Um contador forense, em tese, é treinado e possui expertise em investigar e resolver suspeitas ou alegações de fraude por meio da análise de documentos para incluir informações financeiras e não financeiras, entrevistas, inquéritos de terceiros, incluindo bancos de dados comerciais (Skalak, Golden, Clayton \& Pill, 2011).

Cabe ressaltar, ainda, a correlação da contabilidade forense com a auditoria no trabalho de prevenção e combate à fraude. Porém, os auditores não têm responsabilidade de planejar e executar procedimentos de auditoria para detectar erros que não são considerados significativos (incluindo aqueles causados por erro, bem como a fraude). A gestão empresarial também aumentou a responsabilidade de projetar e implementar controles internos para prevenir e detectar a fraude como resultado da Lei Sarbanes-Oxley (West Virginia University [WVU], 2007).

A contabilidade forense complementa o gap existente na expectativa do resultado da auditoria, o qual gera debates sobre uma série de questões, como, por exemplo: (1) o papel e responsabilidades dos auditores; (2) a natureza e o significado dos comunicados dos relatórios de auditoria; (3) a qualidade da função do auditor; e (4) a estrutura e regulação da profissão (Humphrey, Mozier \& Turley, 1993). A inter-relação entre a auditoria, fraude e contabilidade forense é dinâmica, que vem mudando ao longo do tempo devido aos acontecimentos políticos, sociais e culturais. Além disso, muitas vezes, o conjunto de habilidades exigidos em uma área é capaz de alavancar as habilidades e capacidades ao trabalhar em outra área (WVU, 2007).

Em relação às habilidades necessárias para desempenhar a função de contador forense, há a necessidade de apresentar soluções para as manobras contábeis complicadas que têm ofuscado as demonstrações financeiras. Habilidades de contabilidade forense estão se tornando cada vez mais invocadas dentro de um sistema de comunicação empresarial que enfatiza sua prestação de contas e responsabilidade das partes interessadas (Bhasin, 2013). Habilidade é a capacidade de execução de alguma atividade, é o modo de empreender uma ação de forma mais rápida, fácil e eficiente. É uma capacidade desenvolvida por meio de treinamento, técnicas, métodos, regras e exercícios de natureza física, motora e psicossocial. Similarmente às competências, a habilidade é influenciada pela natureza humana e varia de indivíduo para indivíduo, em função das características pessoais inatas (Peleias, 2006).

Com base na literatura, foi possível identificar o seguinte conjunto de habilidades investigadas com o fim de evidenciar a importância para execução da contabilidade forense, conforme pode ser verificado na Tabela 1: 
Tabela 1

\section{Habilidades Investigadas e Fontes de Pesquisa}

\begin{tabular}{|c|c|c|}
\hline Item & Habilidade & Origem \\
\hline 1 & $\begin{array}{l}\text { Análise dedutiva - habilidade de focar em contradições financeiras que } \\
\text { não se enquadram no padrão normal de uma tarefa. }\end{array}$ & $\begin{array}{l}\text { Digabriele, 2008; Astutie e Utami, } \\
2013 .\end{array}$ \\
\hline 2 & $\begin{array}{l}\text { Pensamento crítico - capacidade de decifrar a diferença entre opinião e } \\
\text { o fato. }\end{array}$ & $\begin{array}{l}\text { Digabriele, 2008; Davis et al., 2010; } \\
\text { Bhasin, 2013; Astutie e Utami, 2013; }\end{array}$ \\
\hline 3 & $\begin{array}{l}\text { Resolução de problemas não estruturados - capacidade de abordar } \\
\text { cada situação (única) e preparado para resolver problemas com } \\
\text { abordagem não estruturada. }\end{array}$ & $\begin{array}{l}\text { Digabriele, 2008, Davis et al., 2010; } \\
\text { Bhasin, 2013; }\end{array}$ \\
\hline 4 & $\begin{array}{l}\text { Flexibilidade Técnica - capacidade de afastar-se de procedimentos } \\
\text { padronizados e examinar cuidadosamente as situações pelos sinais de } \\
\text { alertas atípicos. }\end{array}$ & Digabriele, 2008; \\
\hline 5 & $\begin{array}{l}\text { Proficiência analítica - capacidade de examinar o que deve ser fornecido } \\
\text { ao invés do que é fornecido (análise de viabilidade). }\end{array}$ & Digabriele, 2008 \\
\hline 6 & $\begin{array}{l}\text { Comunicação oral - capacidade de comunicar de forma eficaz no discurso } \\
\text { via depoimento de um especialista e explicação geral das bases de } \\
\text { opinião. }\end{array}$ & $\begin{array}{l}\text { Digabriele, 2008; Davis et al., 2010; } \\
\text { Bhasin, 2013; Astutie e Utami, 2013; }\end{array}$ \\
\hline 7 & $\begin{array}{l}\text { Comunicação escrita - capacidade de comunicar de forma eficaz, por } \\
\text { escrito, por meio de relatórios, tabelas, gráficos e as bases da opinião. }\end{array}$ & $\begin{array}{l}\text { Digabriele, 2008; Davis et al., 2010; } \\
\text { Bhasin, 2013; Astutie e Utami, 2013; }\end{array}$ \\
\hline 8 & $\begin{array}{l}\text { Conhecimento jurídico específico - capacidade de compreender os } \\
\text { procedimentos legais básicos e questões jurídicas, incluindo as regras de } \\
\text { provas. }\end{array}$ & $\begin{array}{l}\text { Digabriele, 2008; Bhasin, 2013; } \\
\text { Davis et al. 2010; Astutie e Utami, } \\
\text { 2013; }\end{array}$ \\
\hline 9 & $\begin{array}{l}\text { Serenidade - capacidade de manter uma atitude calma em situações de } \\
\text { pressão. }\end{array}$ & Digabriele, 2008; \\
\hline 10 & $\begin{array}{l}\text { Rastreamento de ativos - capacidade de identificar bens ou valores } \\
\text { ocultos ou dissimulados. }\end{array}$ & Davis et al., 2010. \\
\hline 11 & Habilidade de entrevista - capacidade de obter testemunho pessoal. & Davis et al., 2010. \\
\hline 12 & $\begin{array}{l}\text { Habilidade investigativa - capacidade de possuir alto nível de atitude } \\
\text { questionadora. Se dispor a investigar opiniões e/ou fatos que podem } \\
\text { sugerir fraude. }\end{array}$ & Davis et al., 2010; Bhasin, 2013; \\
\hline 13 & $\begin{array}{l}\text { Resolução e negociação de conflitos - capacidade de solucionar } \\
\text { controvérsias. }\end{array}$ & Davis et al., 2010. \\
\hline
\end{tabular}

Fonte: elaborada pelos autores.

Digabriele (2008) investigou habilidades relevantes para os contadores forenses, com base na percepção dos profissionais forenses contábeis, dos acadêmicos de contabilidade e dos usuários dos serviços de contabilidade forense. Encontrou que o pensamento crítico, a análise dedutiva e a comunicação escrita são as mais relevantes, enquanto que o conhecimento jurídico específico, a serenidade e a resolução de problemas não estruturados estão entre as habilidades menos relevantes. Ainda, com base na análise dos componentes principais, o autor identificou dois grupos, os quais foram denominados "conhecimento e habilidade" e "desempenho".

Astutie e Utami (2013), com base em pesquisa realizadas com contadores forenses, acadêmicos, advogados e sociedade, encontraram que as habilidades mais relevantes são a flexibilidade investigativa, a análise e síntese de resultados descobertos e o conhecimento legal e perspicácia. Davis et al. (2010) investigaram dezessete habilidades, com base em respondentes advogados, acadêmicos e contadores forenses, e as habilidades mais relevantes encontradas foram pensamento crítico e estratégico, comunicação oral, capacidade de simplificar informação e comunicação escrita. 


\section{Metodologia}

A pesquisa é classificada como descritiva, na medida em que expõe as percepções de parte da população analisada em relação às habilidades esperadas de um perito criminal federal contábil em comparação com as habilidades identificadas na literatura internacional para a contabilidade forense, estabelecendo correlações entre algumas variáveis de estudo e as percepções apuradas (Oliveira, 2011).

\subsection{População pesquisada}

O presente estudo foi realizado no âmbito do Sistema Nacional de Criminalística, englobando os peritos criminais federais, formados em Contabilidade e/ou Economia, em um universo de 250 profissionais.

Considerando que a pesquisa pretendeu identificar a percepção do maior grupo de usuários dos laudos contábeis, a pesquisa também foi aplicada aos delegados da Polícia Federal, buscando identificar, de acordo com as suas necessidades, as habilidades que serão discutidas neste estudo. Atualmente, estima-se que 450 delegados da Polícia Federal no Brasil atuam nas delegacias de crimes financeiros, como previdenciários, desvio de recursos públicos, sonegação fiscal, lavagem de dinheiro e fraudes em licitações.

\subsection{Coleta de Dados}

Para o trabalho de campo, o método de pesquisa utilizado foi o Survey, visto que se utilizou um questionário predefinido, com o intuito de emitir descrições quantitativas de uma população (Freitas, Oliveira, Saccol \& Mascarola, 2000) foram utilizadas questões abertas e fechadas, nas quais os respondentes escolheram entre duas ou mais alternativas fixas apresentadas.

Foi realizado um pré-teste do questionário de pesquisa, em uma amostra, e, com base nas respostas, foi possível executar ajustes na redação das perguntas. O questionário inicial foi submetido, presencialmente, aos peritos e delegados com expertise na área, por serem responsáveis pelas diretrizes da perícia contábil da PF (peritos chefes dos serviços de perícias contábeis e financeiras) ou pelas diretrizes do processo de investigação na área financeira (delegados chefes das delegacias de crimes financeiros), objetivando realizar um teste prévio sobre o conteúdo e sobre a forma. Entre os ajustes realizados, destaca-se a montagem das perguntas sobre as habilidades investigadas em dois blocos, no primeiro, questionando a percepção sobre a importância das habilidades; e no segundo, questionando sobre a percepção da aplicação prática das habilidades.

Optou-se por questões fechadas em que foi discutida a percepção da importância e da existência das habilidades para os peritos criminais no exercício da perícia contábil criminal, no intuito de se produzir um instrumento que pudesse, em um espaço relativamente curto de tempo, atingir um número significativo de pesquisados (Lakatos \& Marconi, 2003). Porém, foram incluídas questões abertas para absorver as opiniões sobre habilidades consideradas necessárias pelos respondentes, que, eventualmente, não foram listadas nos estudos de referência.

Foi escolhida a escala do tipo Likert, pois tal escala permite apresentar um conjunto de itens em forma de afirmações. Tais afirmações foram apresentadas aos pesquisados para que eles se manifestassem da seguinte forma: "não se aplica", "discordo", "discordo parcialmente", "neutro", "concordo parcialmente" ou "concordo". O questionário foi dividido em quatro partes: a primeira parte objetivou traçar um perfil dos pesquisados e possuía informações básicas, como: cargo, gênero, faixa etária, nível de formação acadêmica, área de formação e tempo de experiência no cargo; a segunda parte do questionário objetivou identificar o nível de importância atribuído às habilidades definidas nos estudos recentes sobre contabilidade forense para a perícia contábil criminal federal, na percepção dos executores e dos principais usuários dessa informação. 
Visando aproveitar a experiência prática dos respondentes e com vistas a ampliar a compreensão dessa temática, mesmo em relação às pesquisas internacionais (Digrabiele, 2008; Davis et al., 2010. Astutie \& Utami, 2013), foi criada uma terceira parte no questionário, a qual objetivou verificar qual a percepção do nível atual de existência das mesmas habilidades na perícia contábil criminal federal. Por fim, foi apresentada uma questão aberta, representando a quarta parte do questionário, na qual se objetivou deixar os respondentes livres para sugerirem sobre a importância e a existência de outras habilidades não listadas, mas que devem ser correlacionadas com a atividade de perícia contábil criminal federal.

Foram enviados 350 questionários eletrônicos via e-mail (formulário Google) e aplicados formulários físicos, conforme pode ser verificado no Apêndice A (Brasília, Espírito Santo, Rio de Janeiro, Rio Grande do Norte e Alagoas), sendo obtidas 152 respostas, 44 formulários físicos e 108 formulários eletrônicos. Foram descartados oito formulários físicos, em razão da falta de respostas em alguns quesitos. A amostra final contou com o total de 144 respondentes, sendo 93 peritos e 51 delegados.

\subsection{Testes aplicados}

Considerando os meios escolhidos e os objetivos traçados, os dados quantitativos foram analisados, de forma a permitir uma comparação com os resultados obtidos em estudos anteriores (Digrabiele, 2008; Davis et al., 2010. Astutie \& Utami, 2013), os quais utilizaram do teste de ANOVA, da seguinte forma:

a) Para realizar comparativo das diferenças de percepções dos dois grupos analisados (praticantes e usuários da perícia contábil criminal) em relação às habilidades importantes e às existentes, foi utilizado o teste Qui-Quadrado de Pearson. Esses testes são considerados adequados, quando se busca verificar se duas variáveis são independentes, ou seja, eles avaliam se duas ou mais amostras independentes diferem relativamente em determinada característica (Bracarense, 2012). Dessa maneira, a análise quantitativa identificou e quantificou pontos que indicaram ou auxiliaram a captação e a interpretação das percepções dos pesquisados sobre o assunto, demonstrando se eles reconhecem como pertinentes alguns aspectos apontados na pesquisa bibliográfica realizada, bem como a comparação entre eles.

b) No tocante aos dados qualitativos (questão aberta), foi realizada a análise de conteúdo como um conjunto de instrumentos metodológicos em constante aperfeiçoamento, os quais se aplicam às diversas formas de comunicação existente (Bardin, 1997). A análise de conteúdo realizada no presente estudo foi baseada no cálculo de frequências das habilidades adicionais citadas (Bardin, 1977), seguida de sua interpretação das mesmas, associando os resultados ao referencial teórico utilizado.

\section{Resultados Encontrados e Análise}

\subsection{Perfil característico da amostra pesquisada}

Foram enviados 350 questionários, dos quais 152 foram respondidos (43,43\%), destes foram descartados 8, sendo aproveitados 144, dos quais 51 (35,42\%) foram do cargo de Delegado de Polícia Federal e $93(64,58 \%)$ do cargo de perito Criminal Federal e, ainda, 90,28\% dos pesquisados são do gênero masculino e $9,72 \%$ dos respondentes representados por mulheres. 
No que se refere à faixa etária dos respondentes, metade tem idade entre 31-40 anos (50\%), seguidos 41-50 anos (33,33\%). Quanto ao nível de formação, 44,44\% tem bacharelado, seguido de especialização latu sensu com $34,72 \%$, mestrado com 13,89\% e apenas dois possuem o doutorado, o que representa 1,39\%. Em relação ao tempo de experiência em seus respectivos cargos, a maioria dos pesquisados possui entre 6-10 anos (56,25\%), seguido de 11-15 (27,08\%).

A concentração geográfica dos pesquisados por região foi Centro-Oeste (37,5\%), Nordeste (26,24\%), Sudeste (22,2\%), Norte $(7,6 \%)$ e Sul $(6,2 \%)$. Vale destacar que houve participação de respondentes de todos os estados da Federação e do Distrito Federal, com maioria do Distrito Federal (25,69\%), seguido do Rio de Janeiro $(9,03 \%)$.

No que tange à formação, $13,73 \%$ dos delegados e $16,13 \%$ dos peritos possuem uma segunda formação. A maior parte dos peritos tem formação em Contabilidade (83,87\%), seguida de Economia (13,98\%) e apenas dois peritos possuem formação em Economia e Contabilidade ao mesmo tempo (2,15\%). Foi evidenciado que quatorze peritos possuem formação em Direito $(15,05 \%)$.

\subsection{Estatística descritiva}

Para identificar a percepção da importância e aplicação prática das habilidades, segundo os respondentes, foram consolidados os dados de três formas: percepção agregada dos usuários e praticantes; percepção apenas dos praticantes; e percepção apenas dos usuários. Primeiramente, foi calculado o coeficiente alfa de Cronbach para verificar a confiabilidade do questionário utilizado na pesquisa. Constatou-se que, na avaliação da importância e aplicação prática das habilidades, há confiabilidade nos questionários, conforme os resultados 0,81 e 0,91 , respectivamente.

\subsubsection{Percepção conjunta da importância das habilidades}

No que tange à visão conjunta dos praticantes e dos usuários, de acordo com a Tabela 02 , as três habilidades mais importantes foram: ( $\left.1^{a}\right)$ comunicação escrita, $\left(2^{a}\right)$ análise dedutiva e ( $\left.3^{a}\right)$ pensamento crítico. Essa constatação ficou alinhada com a pesquisa de Digabriele (2008), com divergência apenas de ordem, onde apontou como habilidades mais importantes $\left(1^{\mathrm{a}}\right)$ pensamento crítico, $\left(2^{\mathrm{a}}\right)$ análise dedutiva e ( $\left.3^{a}\right)$ comunicação escrita.

As divergências relevantes foram verificadas em relação ao estudo de Astutie e Utami (2013), verifica-se a seguinte escala de importância das habilidades investigadas: ( $1^{a}$ ) flexibilidade técnica, a segunda colocada não foi objeto desta pesquisa e ( $\left.3^{a}\right)$ conhecimento legal e específico. A convergência identificada com o estudo de Digabriele (2008), tanto para as atividades consideradas mais relevantes como menos relevantes, pode ser resultado da aproximação dos procedimentos nacionais com as bases das teorias e práticas adotadas pelos americanos, inclusive no que se refere à proximidade da Polícia Federal com o Federal Bureau of Investigation (FBI). 
Tabela 2

Percepção dos usuários e praticantes sobre a importância das habilidades e pesquisas internacionais

\begin{tabular}{|c|c|c|c|c|c|}
\hline \multicolumn{4}{|c|}{ Praticantes e usuários ( $\mathrm{N}=144)$} & \multirow{2}{*}{$\begin{array}{l}\text { Digabriele } \\
(2008)\end{array}$} & \multirow{2}{*}{$\begin{array}{c}\text { Astutie e Utami } \\
\text { (2013) }\end{array}$} \\
\hline I - Importância das atividades & Média & Desvio Padrão & Ranking & & \\
\hline Comunicação escrita & 4,85 & 0,49 & 1 & 3 & 7 \\
\hline Análise dedutiva & 4,75 & 0,60 & 2 & 2 & $\star \star *$ \\
\hline Pensamento crítico & 4,72 & 0,65 & 3 & 1 & 4 \\
\hline Rastreamento de ativos & 4,69 & 0,65 & 4 & * & ** \\
\hline Flexibilidade técnica & 4,59 & 0,79 & 5 & 5 & 1 \\
\hline $\begin{array}{l}\text { Resolução de problemas não } \\
\text { estruturados }\end{array}$ & 4,56 & 0,75 & 6 & 7 & ** \\
\hline Proficiência analítica & 4,50 & 0,92 & 7 & 4 & ** \\
\hline Serenidade & 4,38 & 0,97 & 8 & 8 & ** \\
\hline Investigativa & 4,10 & 1,24 & 9 & * & $* \star$ \\
\hline Comunicação oral & 4,00 & 1,15 & 10 & 6 & 7 \\
\hline Conhecimento jurídico específico & 3,91 & 1,16 & 11 & 9 & 3 \\
\hline Resolução de conflitos & 3,49 & 1,40 & 12 & * & ** \\
\hline Entrevista & 3,16 & 1,50 & 13 & * & ** \\
\hline
\end{tabular}

Fonte: dados da pesquisa. Notas: * Habilidades não investigadas por Digabriele (2008); ** Habilidades não investigadas por Astutie e Utami (2013), que ainda investigou as habilidades análise e síntese do resultado encontrado $\left(2^{\circ}\right)$, detalhista $\left(5^{\circ}\right)$ e Ceticismo $\left(6^{\circ}\right)$

O estudo de Digabriele (2008) investigou nove habilidades, e o de Astutie e Utami (2013) investigou sete habilidades variáveis que podem influenciar na comparação dos resultados. As habilidades apontadas como mais relevantes pelos respondentes são achados que podem ser importantes para a capacitação dos profissionais e formação de estudantes. Cabe ressaltar ainda a comunicação escrita, habilidade essencial para a produção dos laudos periciais.

As habilidades ranqueadas como menos importantes na visão conjunta dos usuários e praticantes foram: $\left(13^{\circ}\right)$ entrevista, $\left(12^{\circ}\right)$ resolução e negociação de conflitos e $\left(11^{\circ}\right)$ conhecimento jurídico específico. Digabriele (2008) apontou como habilidades menos relevantes entre as nove investigadas, $\left(9^{\circ}\right)$ conhecimento jurídico específico, $\left(8^{\circ}\right)$ serenidade e $\left(7^{\circ}\right)$ resolução de problemas não estruturados. $O$ resultado de Astutie e Utami (2013) apresentou as seguintes habilidades como menos relevantes dentre as sete investigadas: $\left(7^{\circ}\right)$ comunicação oral e escrita, $\left(6^{\circ}\right)$ ceticismo e $\left(5^{\circ}\right)$ detalhista.

O número diferente de quantidade de habilidades pesquisadas pode provocar distorções na comparação das menos relevantes, haja vista o estudo de Astutie e Utami (2013) apresentar a comunicação oral e escrita como as menos relevantes, quando se depreende que o produto do perito criminal é o laudo, em que a habilidade de escrita deverá ser evidenciada.

\subsubsection{Percepção conjunta da aplicação prática das habilidades}

Em relação à percepção conjunta dos usuários e praticantes quanto à aplicação prática das habilidades investigadas, na Tabela 3, foram classificadas como mais presentes: $\left(1^{\circ}\right)$ comunicação escrita, $\left(2^{\circ}\right)$ análise dedutiva e $\left(3^{\circ}\right)$ pensamento crítico. Cabe ressaltar que as três primeiras mais importantes são iguais as três primeiras mais existentes, na mesma ordem de classificação. No entanto, verifica-se que os respondentes foram mais críticos na percepção da existência das habilidades ao ficar constatado a redução da média em comparação com as médias da importância dessas mesmas habilidades. 
Tabela 3

Percepção dos usuários e praticantes sobre a aplicação prática das habilidades

\begin{tabular}{lcccccc}
\hline & \multicolumn{7}{c}{ Praticantes e usuários (N=144) } & \\
\hline Aplicação prática das habilidades & Média & $\begin{array}{c}\text { Desvio } \\
\text { padrão }\end{array}$ & Aplicação prática das habilidades & Média & $\begin{array}{c}\text { Desvio } \\
\text { padrão }\end{array}$ \\
\hline Comunicação escrita & 3,97 & 1,02 & Flexibilidade técnica & 3,52 & 1,25 \\
\hline Análise dedutiva & 3,90 & 1,15 & Comunicação oral & 3,10 & 1,23 \\
\hline Pensamento crítico & 3,87 & 1,10 & Investigativa & 3,06 & 1,36 \\
\hline Serenidade & 3,71 & 1,10 & Resolução e negociação de conflitos & 2,92 & 1,21 \\
\hline $\begin{array}{l}\text { Resolução de problemas não } \\
\text { estruturados }\end{array}$ & 3,61 & 1,17 & Conhecimento jurídico específico & 2,86 & 1,27 \\
\hline Rastreamento de ativos & 3,55 & 1,18 & Entrevista & 2,68 & 1,35 \\
\hline Proficiência analítica & 3,53 & 1,33 & & - & - \\
\hline
\end{tabular}

Fonte: dados da pesquisa.

Em relação às habilidades menos percebidas pelos respondentes, estão: a $\left(13^{\circ}\right)$ entrevista e $\left(12^{\circ}\right)$ conhecimento jurídico específico. Nesse caso, o aparecimento do conhecimento jurídico específico entre as habilidades menos presentes pode ser considerado como motivo de atenção para os gestores do Sistema de Criminalística e para os formadores de contadores forenses, pois o conhecimento jurídico específico consiste na capacidade de compreender os procedimentos legais básicos e questões jurídicas, incluindo as regras de provas, o que pode ser essencial para o exercício da atividade.

\subsection{Comparativo entre a percepção de usuários e praticantes da perícia contábil forense}

Foram aplicados testes não paramétricos para a comparação das medianas (soma dos postos de Wilcoxon) para investigar se há diferença na percepção dos usuários e praticantes em relação à importância e à aplicação prática das habilidades.

\subsubsection{Diferença de percepção entre usuários e praticantes quanto à importância das habilidades}

Para a importância das habilidades investigadas, é possível observar, na Tabela 04, a diferença significativa ( $95 \%$ de confiança) em cinco habilidades, demonstrando que as medianas dos peritos são superiores às dos delegados, quais sejam: "conhecimento jurídico específico", "investigativa", "entrevista", "serenidade" e "pensamento crítico". 
Tabela 4

Comparativo entre a percepção dos usuários e praticantes sobre a importância das habilidades

\begin{tabular}{|c|c|c|c|c|c|c|}
\hline \multirow{2}{*}{ Variáveis da importância das habilidades } & \multicolumn{2}{|c|}{ Usuário (N=51) } & \multicolumn{2}{|c|}{$\begin{array}{l}\text { Praticante } \\
(\mathrm{N}=93)\end{array}$} & \multicolumn{2}{|c|}{ Diferença } \\
\hline & Média & $\begin{array}{l}\text { Desvio } \\
\text { padrão }\end{array}$ & Média & $\begin{array}{l}\text { Desvio } \\
\text { padrão }\end{array}$ & z & Valor-P \\
\hline Análise dedutiva & 4,76 & 0,62 & 4,74 & 0,59 & 0,71 & 0,48 \\
\hline Pensamento crítico & 4,51 & 0,92 & 4,84 & 0,40 & $-2,45$ & $0,01 *$ \\
\hline Resolução de problemas não estruturados & 4,39 & 0,96 & 4,66 & 0,58 & $-1,53$ & 0,12 \\
\hline Flexibilidade técnica & 4,67 & 0,62 & 4,55 & 0,87 & 0,60 & 0,55 \\
\hline Proficiência analítica & 4,25 & 1,29 & 4,63 & 0,60 & $-1,02$ & 0,30 \\
\hline Comunicação oral & 4,12 & 1,32 & 3,94 & 1,05 & 1,88 & 0,06 \\
\hline Comunicação escrita & 4,90 & 0,41 & 4,82 & 0,53 & 1,27 & 0,20 \\
\hline Conhecimento jurídico específico & 3,37 & 1,25 & 4,20 & 1,01 & $-4,18$ & $0,00 *$ \\
\hline Serenidade & 4,10 & 1,14 & 4,53 & 0,84 & $-2,62$ & $0,00 *$ \\
\hline Rastreamento de ativos & 4,69 & 0,81 & 4,70 & 0,55 & 0,90 & 0,36 \\
\hline Entrevista & 2,59 & 1,70 & 3,47 & 1,28 & $-3,03$ & $0,00 *$ \\
\hline Investigativa & 3,55 & 1,54 & 4,41 & 0,92 & $-3,63$ & $0,00 *$ \\
\hline Resolução e negociação de conflitos & 3,20 & 1,59 & 3,65 & 1,27 & $-1,48$ & 0,13 \\
\hline
\end{tabular}

Fonte: dados da pesquisa. Nota: * Significância de 0,05.

As habilidades diárias exigidas do contador forense no âmbito da Polícia Federal são, na maior parte do tempo, executadas internamente, em razão da necessidade de análises documentais e produções dos laudos, o que pode restringir as possibilidades de uso e avaliação por parte dos usuários das habilidades de entrevista e investigação criminal, sendo que esta última não deve ser confundida com a investigação científica realizada diariamente pelos contadores forenses.

\subsubsection{Diferença de percepção entre usuários e praticantes quanto à aplicação pratica das habilidades}

No que tange à percepção da presença das habilidades, na Tabela 5, verifica-se que a mediana dos peritos permaneceu maior para o "conhecimento jurídico específico" e surgiu a "resolução de problemas não estruturados". Já a mediana dos delegados foi maior para as habilidades "entrevista" e "serenidade". 
Tabela 5

Comparativo entre a percepção dos usuários e praticantes sobre a aplicação prática das habilidades

\begin{tabular}{lcccccc}
\hline \multirow{2}{*}{ Variáveis da aplicação prática das habilidades } & \multicolumn{2}{c}{ Usuário (N=51) } & Praticante (N=93) & \multicolumn{2}{c}{ Diferença } \\
\cline { 2 - 7 } & Média & $\begin{array}{c}\text { Desvio } \\
\text { padrão }\end{array}$ & Média & $\begin{array}{c}\text { Desvio } \\
\text { padrão }\end{array}$ & Z & Valor-P \\
\hline Análise dedutiva & 3,73 & 1,23 & 4,00 & 1,09 & $-1,25$ & 0,21 \\
\hline Pensamento crítico & 3,65 & 1,18 & 3,99 & 1,05 & $-1,79$ & 0,07 \\
\hline Resolução de problemas não estruturados & 3,35 & 1,21 & 3,75 & 1,13 & $-2,07$ & $0,04^{*}$ \\
\hline Flexibilidade técnica & 3,33 & 1,28 & 3,62 & 1,22 & $-1,42$ & 0,15 \\
\hline Proficiência analítica & 3,47 & 1,41 & 3,56 & 1,30 & $-0,28$ & 0,77 \\
\hline Comunicação oral & 3,22 & 1,30 & 3,04 & 1,20 & 0,69 & 0,49 \\
\hline Comunicação escrita & 4,08 & 1,02 & 3,91 & 1,03 & 1,02 & 0,31 \\
\hline Conhecimento jurídico específico & 2,43 & 1,20 & 3,10 & 1,24 & $-\mathbf{3 , 1 4}$ & $\mathbf{0 , 0 0 *}$ \\
\hline Serenidade & 3,94 & 1,21 & 3,58 & 1,01 & $\mathbf{2 , 1 8}$ & $\mathbf{0 , 0 3 *}$ \\
\hline Rastreamento de ativos & 3,41 & 1,30 & 3,62 & 1,11 & $-0,84$ & 0,40 \\
\hline Entrevista & 2,27 & 1,42 & 2,90 & 1,27 & $\mathbf{2 , 5 4}$ & $\mathbf{0 , 0 1 *}$ \\
\hline Investigativa & 2,80 & 1,47 & 3,21 & 1,28 & $-1,51$ & 0,13 \\
\hline Resolução e negociação de conflitos & 2,69 & 1,29 & 3,05 & 1,16 & $-1,68$ & 0,09 \\
\hline
\end{tabular}

Fonte: dados da pesquisa. Nota: * Significância de 0,05.

O "conhecimento jurídico específico" foi a única habilidade a confirmar uma diferença tanto na percepção da importância quanto na percepção da aplicação prática da habilidade. Considerando ser uma habilidade necessária para o desenvolvimento da contabilidade forense, o resultado revela a necessidade de os peritos criminais informarem melhor aos seus clientes o significado dessa habilidade para realização de suas atividades e desfazer a possibilidade de confusão com atuação jurídica, algo reservado aos bacharéis das Ciências Jurídicas.

\subsection{Correlação de Pearson}

Foi aplicada a correlação de Pearson sobre as variáveis que questionam a importância das habilidades para perícia contábil criminal, com significância valor P menor ou igual a 0,05 . Com base no teste de Pearson, na Tabela 6, as correlações de maiores valores e estatisticamente significantes a 5\% foram: "comunicação escrita" com "análise dedutiva", "resolução e negociação de conflitos" com "entrevista" e "serenidade" com conhecimento jurídico específico. Já as correlações significativas a 5\%, mas com menores valores foram: a "entrevista" e a "flexibilidade técnica", assim como a "serenidade" e a "proficiência analítica". 
Tabela 6

Correlação de Pearson sobre a importância das habilidades*

\begin{tabular}{|c|c|c|c|c|c|c|c|c|c|c|c|c|c|}
\hline Habilidades & 1 & 2 & 3 & 4 & 5 & 6 & 7 & 8 & 9 & 10 & 11 & 12 & 13 \\
\hline 1-Análise dedutiva & --- & & & & & & & & & & & & \\
\hline \multirow{2}{*}{ 2-Pensamento crítico } & 0,31 & --- & & & & & & & & & & & \\
\hline & 0,00 & & & & & & & & & & & & \\
\hline \multirow{2}{*}{$\begin{array}{l}\text { 3-Resolução de problemas } \\
\text { não estruturados }\end{array}$} & 0,22 & 0,35 & --- & & & & & & & & & & \\
\hline & 0,01 & 0,00 & & & & & & & & & & & \\
\hline \multirow{2}{*}{ 4-Flexibilidade técnica } & 0,26 & 0,21 & 0,41 & --- & & & & & & & & & \\
\hline & 0,00 & 0,01 & 0,00 & & & & & & & & & & \\
\hline \multirow{2}{*}{ 5-Proficiência analítica } & 0,13 & 0,21 & 0,25 & 0,35 & --- & & & & & & & & \\
\hline & 0,13 & 0,01 & 0,00 & 0,00 & & & & & & & & & \\
\hline \multirow{2}{*}{ 6-Comunicação oral } & 0,28 & 0,14 & 0,12 & 0,15 & 0,27 & --- & & & & & & & \\
\hline & 0,00 & 0,10 & 0,14 & 0,07 & 0,00 & & & & & & & & \\
\hline \multirow{2}{*}{ 7-Comunicação escrita } & 0,49 & 0,32 & 0,35 & 0,32 & 0,20 & 0,31 & --- & & & & & & \\
\hline & 0,00 & 0,00 & 0,00 & 0,00 & 0,02 & 0,00 & & & & & & & \\
\hline \multirow{2}{*}{$\begin{array}{l}\text { 8-Conhecimento jurídico } \\
\text { específico }\end{array}$} & 0,15 & 0,17 & 0,30 & 0,06 & 0,28 & 0,39 & 0,22 & --- & & & & & \\
\hline & 0,08 & 0,04 & 0,00 & 0,49 & 0,00 & 0,00 & 0,01 & & & & & & \\
\hline \multirow{2}{*}{ 9-Serenidade } & 0,27 & 0,35 & 0,45 & 0,12 & 0,16 & 0,19 & 0,28 & 0,48 & --- & & & & \\
\hline & 0,00 & 0,00 & 0,00 & 0,15 & 0,05 & 0,03 & 0,00 & 0,00 & & & & & \\
\hline \multirow{2}{*}{ 10-Rastreamento de ativos } & 0,27 & 0,16 & 0,31 & 0,37 & 0,29 & 0,34 & 0,36 & 0,31 & 0,16 & --- & & & \\
\hline & 0,00 & 0,05 & 0,00 & 0,00 & 0,00 & 0,00 & 0,00 & 0,00 & 0,06 & & & & \\
\hline \multirow{2}{*}{ 11-Entrevista } & 0,14 & 0,32 & 0,28 & 0,16 & 0,22 & 0,35 & 0,12 & 0,47 & 0,38 & 0,25 & --- & & \\
\hline & 0,10 & 0,00 & 0,00 & 0,05 & 0,01 & 0,00 & 0,16 & 0,00 & 0,00 & 0,00 & & & \\
\hline \multirow{2}{*}{ 12-Investigativa } & 0,18 & 0,34 & 0,22 & 0,25 & 0,12 & 0,24 & 0,26 & 0,31 & 0,15 & 0,41 & 0,44 & --- & \\
\hline & 0,03 & 0,00 & 0,01 & 0,00 & 0,16 & 0,00 & 0,00 & 0,00 & 0,08 & 0,00 & 0,00 & & \\
\hline \multirow{2}{*}{$\begin{array}{l}\text { 13-Resolução e negociação de } \\
\text { conflitos }\end{array}$} & 0,12 & 0,27 & 0,25 & 0,25 & 0,24 & 0,33 & 0,21 & 0,35 & 0,32 & 0,22 & 0,49 & 0,33 & --- \\
\hline & 0,15 & 0,00 & 0,00 & 0,00 & 0,00 & 0,00 & 0,01 & 0,00 & 0,00 & 0,01 & 0,00 & 0,00 & \\
\hline
\end{tabular}

Fonte: dados da pesquisa. Nota: * significâncias destacadas em itálico

Acerca da correlação mais significativa, a comunicação escrita com a análise dedutiva, depreendese que é necessário que o contador forense não só esteja apto a identificar as contradições financeiras com expertise, mas também deve atentar-se para a capacidade de traduzir de forma eficaz seus achados para o público leigo que fará uso do laudo pericial. No que tange à correlação significativa da resolução e negociação de conflito com a entrevista, pode-se inferir que se trata de habilidades relacionadas à capacidade do contador forense, na execução do seu trabalho, criar um ambiente favorável ao entendimento e à obtenção de informações que podem ser importantes, em razão do estabelecimento da confiança no profissional.

\subsection{Análise dos Componentes Principais}

Foi realizada a análise de componentes principais em relação à percepção da importância das treze habilidades e à percepção de sua existência nos atuais peritos, visando identificar agrupamentos de variáveis e seus significados. 


\subsubsection{Análise dos componentes principais da importância das habilidades}

Em relação à importância das habilidades foram encontrados quatro grupos de componentes principais, após, foi realizada a rotação Varimax.

O primeiro componente rodado tem a soma dos quadrados dos carregamentos de 2,68, explicando $20,65 \%$ da variância entre os treze itens, cinco dos itens tiveram cargas de 0,32 ou maior nesse componente ("comunicação oral", "conhecimento jurídico específico", "habilidade de entrevista", "resolução e negociação de conflitos" e "habilidade investigativa"). Esse componente foi denominado "conhecimento jurídico, investigativo e atitudinal", representa habilidades que exigem conhecimentos das relações jurídicas e das relações interpessoais, as quais podem ser necessárias para formalização e obtenção das provas científicas, na Tabela 7.

Tabela 7

Rotação das cargas dos componentes principais da importância das habilidades

\begin{tabular}{lcccc}
\hline \multicolumn{1}{c}{ Habilidades } & $\begin{array}{c}\text { Conhecimento jurídico, } \\
\text { investigativo e atitudinal }\end{array}$ & $\begin{array}{c}\text { Desempenho } \\
\text { analítico }\end{array}$ & $\begin{array}{c}\text { Reflexão e } \\
\text { estratégia }\end{array}$ & Metodologia \\
\hline Comunicação oral & $\mathbf{0 , 4 9}$ & $-0,09$ & $-0,29$ & 0,29 \\
\hline Conhecimento jurídico específico & 0,47 & $-0,17$ & 0,14 & $-0,02$ \\
\hline Habilidade de entrevista & 0,45 & $-0,01$ & 0,19 & $-0,21$ \\
\hline $\begin{array}{l}\text { Resolução e negociação de } \\
\text { conflitos. }\end{array}$ & 0,36 & 0,11 & 0,14 & $-0,18$ \\
\hline Habilidade investigativa & 0,32 & 0,19 & $-0,03$ & $-0,02$ \\
\hline Flexibilidade técnica & $-0,11$ & 0,67 & 0,02 & 0,02 \\
\hline Proficiência analítica & 0,14 & 0,45 & $-0,04$ & $-0,12$ \\
\hline Rastreamento de ativos & 0,25 & 0,35 & $-0,24$ & 0,19 \\
\hline Resolução de problemas não & $-0,09$ & 0,31 & 0,47 & 0,01 \\
\hline estruturados & 0,12 & $-0,18$ & 0,57 & 0,09 \\
\hline Perenidade & $-0,03$ & 0,07 & 0,47 & 0,13 \\
\hline Análise dedutiva & $-0,01$ & $-0,05$ & 0,06 & $\mathbf{0 , 6 6}$ \\
\hline Comunicação escrita & 0,00 & 0,11 & 0,06 & $\mathbf{0 , 5 7}$ \\
\hline Soma do quadrado das cargas & 2,68 & 1,81 & 1,78 & 1,63 \\
\hline Percentagem da variância explicada & 20,65 & 13,89 & 13,69 & 12,54 \\
\hline
\end{tabular}

Fonte: dados da pesquisa.

O segundo componente rodado tem a soma dos quadrados dos carregamentos de 1,81, explicando $13,89 \%$ da variância entre os treze itens, quatro dos itens tiveram cargas de 0,31 ou maior nesse componente ("flexibilidade técnica", "proficiência analítica", "rastreamento de ativos" e "resolução de problemas não estruturados"). Este componente foi denominado "desempenho analítico" e se trata de um grupo com viés técnico da contabilidade forense.

O terceiro componente rodado tem a soma dos quadrados dos carregamentos de 1,78, explicando $13,69 \%$ da variância entre os treze itens, três dos itens tiveram cargas de 0,47 ou superior neste componente ("resolução de problemas não estruturados", "serenidade" e "pensamento crítico"). Esse componente foi denominado "reflexão e estratégia", pois abrange habilidades que podem contribuir para a definição de estratégias técnicas, visando à solução de problemas no exercício da contabilidade forense. 
Por fim, o quarto componente rodado tem a soma dos quadrados dos carregamentos de 1,63, explicando $12,54 \%$ da variância entre os treze itens, dois dos itens tiveram cargas de 0,57 ou maior nesse componente ("análise dedutiva" e "comunicação escrita"). Este componente foi denominado "metodologia", já que envolve habilidades de análise e comunicação, as quais podem contribuir para eficácia na solução de contradições financeiras e em se comunicar com o demandante da perícia contábil criminal.

Juntos, os quatro componentes são responsáveis por $60,76 \%$ da variância entre os treze itens da importância das habilidades. No que tange à comparação com as pesquisas internacionais, verifica-se que Digabriele, 2008 processou a Análise dos Componentes Principais e encontrou dois grupos relevantes, quais sejam:

a) Conhecimento e habilidade, formado pelas habilidades: análise dedutiva; pensamento crítico; resolução de problemas não estruturados; flexibilidade investigativa; e proficiência analítica;

b) Desempenho, formado pelas habilidades: comunicação oral; comunicação escrita; conhecimento jurídico específico; e serenidade.

\subsubsection{Análise dos componentes principais da percepção da aplicação prática das habilidades}

Em relação à percepção da aplicação prática das habilidades, foram encontrados três grupos de componentes principais, após, foi realizada a rotação Varimax.

O primeiro componente rodado tem a soma dos quadrados dos carregamentos de 3,48 , explicando $26,81 \%$ da variância entre os treze itens, cinco dos itens tiveram cargas de 0,38 ou maior nesse componente ("análise dedutiva", "pensamento crítico", "resolução de problemas não estruturados", "flexibilidade técnica" e "proficiência analítica"). Este componente foi denominado "desempenho analítico e estratégico", pois representa habilidades que permite ao contador forense o domínio das técnicas analíticas necessárias para solução do caso sob exame, permitindo, dessa forma, o estabelecimento de estratégia adequada, conforme Tabela 8 . 
Tabela 8

Rotação Varimax das variáveis da aplicação prática das habilidades

\begin{tabular}{lccc}
\hline \multicolumn{1}{c}{ Habilidades } & $\begin{array}{c}\text { Desempenho analítico e } \\
\text { estratégico }\end{array}$ & $\begin{array}{c}\text { Comunicação e } \\
\text { serenidade }\end{array}$ & Diligência \\
\hline Análise dedutiva & 0,49 & 0,10 & $-0,18$ \\
\hline $\begin{array}{l}\text { Resolução de problemas } \\
\text { não estruturados }\end{array}$ & $\mathbf{0 , 4 8}$ & $-0,06$ & 0,04 \\
\hline Flexibilidade técnica & 0,47 & $-0,17$ & 0,12 \\
\hline Proficiência analítica & 0,38 & 0,03 & 0,05 \\
\hline Pensamento crítico & 0,37 & 0,12 & $-0,05$ \\
\hline Comunicação escrita & 0,02 & 0,59 & $-0,14$ \\
\hline Comunicação oral & $-0,11$ & 0,51 & 0,10 \\
\hline Serenidade & 0,03 & 0,40 & $-0,01$ \\
\hline Entrevista & $-0,07$ & $-0,02$ & 0,59 \\
\hline Investigativa & 0,05 & $-0,05$ & 0,53 \\
\hline $\begin{array}{l}\text { Resolução e negociação de } \\
\text { conflitos }\end{array}$ & 0,05 & 0,00 & 0,46 \\
\hline Rastreamento de ativos & 0,09 & 0,29 & 0,17 \\
\hline $\begin{array}{l}\text { Conhecimento jurídico } \\
\text { específico }\end{array}$ & 0,04 & 0,27 & 0,23 \\
\hline $\begin{array}{l}\text { Soma do quadrado das } \\
\text { cargas }\end{array}$ & 3,48 & 2,55 & 2,53 \\
\hline $\begin{array}{l}\text { Percentagem da variância } \\
\text { explicada }\end{array}$ & 26,81 & 19,66 & 19,51 \\
\hline
\end{tabular}

Fonte: dados da pesquisa.

O segundo componente rodado tem a soma dos quadrados dos carregamentos de 2,55, explicando $19,66 \%$ da variância entre os treze itens, três dos itens tiveram cargas de 0,40 ou maior neste componente ("comunicação oral", "comunicação escrita" e "serenidade"). Este componente foi denominado "comunicação e serenidade", pois representa habilidades que permitem ao contador forense informar os achados em razão dos exames periciais, mesmo em situações de pressão, como, por exemplo, em um caso de depoimento em um tribunal.

O terceiro componente rodado tem a soma dos quadrados dos carregamentos de 2,53, explicando $19,51 \%$ da variância entre os treze itens, três dos itens tiveram carga de 0,46 ou maior neste componente ("entrevista", "investigativa" e "resolução e negociação de conflitos"). Este componente foi denominado "diligência", pois são habilidades que estão relacionadas com a necessidade de o contador forense buscar informações e/ou soluções.

Juntos, os três componentes são responsáveis por 65,99\% da variância entre os treze itens da existência das habilidades. 


\section{Outras habilidades apontadas como importantes}

Foi solicitado aos respondentes a indicação de três habilidades consideradas importantes para o desenvolvimento da atividade de perícia contábil criminal federal e que não estavam listadas nas questões anteriores. Logo em seguida foi solicitado que eles avaliassem a percepção da aplicação prática das habilidades sugeridas pelos próprios respondentes. Não era obrigatório o apontamento de três habilidades, podia ser 0, 1, 2 ou 3, o que resultou em 194 itens de habilidades sugeridas. Como os respondentes ficaram à vontade para escrever, houve a necessidade de resumir algumas habilidades e juntar outras correlacionadas, visando à consolidação dos dados.

Na Tabela 9 são apresentadas as 16 habilidades mais sugeridas e as respectivas avaliações realizadas pelos respondentes. Foram selecionadas até as habilidades apontadas por pelo menos três respondentes.

Tabela 9

Ranking das principais habilidades não investigadas e sugeridas como importantes (em \%)

\begin{tabular}{|c|c|c|c|c|c|c|}
\hline Principais habilidades sugeridas & Discordo & $\begin{array}{c}\text { Discordo } \\
\text { parcialmente }\end{array}$ & Neutro & $\begin{array}{c}\text { Concordo } \\
\text { parcialmente }\end{array}$ & Concordo & $\begin{array}{l}\text { Frequência } \\
\text { total* }\end{array}$ \\
\hline Proatividade & 13,33 & 13,33 & 20,00 & 46,67 & 6,67 & 15 \\
\hline Objetividade & 15,38 & 15,38 & 15,38 & 53,85 & 0,00 & 13 \\
\hline Atualização & 12,50 & 12,50 & 0,00 & 75,00 & 0,00 & 8 \\
\hline $\begin{array}{l}\text { Integração com a equipe de } \\
\text { investigação }\end{array}$ & 37,50 & 12,50 & 0,00 & 50,00 & 0,00 & 8 \\
\hline Comprometimento & 33,33 & 16,67 & 0,00 & 50,00 & 0,00 & 6 \\
\hline Clareza & 0,00 & 20,00 & 40,00 & 40,00 & 0,00 & 5 \\
\hline Trabalhar em equipe & 0,00 & 0,00 & 20,00 & 80,00 & 0,00 & 5 \\
\hline Celeridade & 50,00 & 25,00 & 25,00 & 0,00 & 0,00 & 4 \\
\hline Uso de planilhas e banco de dados & 0,00 & 0,00 & 25,00 & 50,00 & 25,00 & 4 \\
\hline Análise dedutiva & 33,33 & 0,00 & 33,33 & 0,00 & 33,33 & 3 \\
\hline Concentração & 0,00 & 33,33 & 0,00 & 66,67 & 0,00 & 3 \\
\hline Cooperação & 0,00 & 66,67 & 0,00 & 33,33 & 0,00 & 3 \\
\hline Criatividade & 0,00 & 33,33 & 0,00 & 66,67 & 0,00 & 3 \\
\hline Imparcialidade & 0,00 & 0,00 & 0,00 & 100,00 & 0,00 & 3 \\
\hline Independência & 0,00 & 0,00 & 0,00 & 100,00 & 0,00 & 3 \\
\hline Persistência & 0,00 & 33,33 & 0,00 & 66,67 & 0,00 & 3 \\
\hline
\end{tabular}

Fonte: dados da pesquisa. Nota: *A coluna "Frequência total" não está em percentual.

A habilidade mais lembrada pelos respondentes foi a "proatividade", em segundo ficou a "objetividade" e em terceiro ficaram a "atualização" e a "integração" com a equipe de investigação. Destaca-se que essas habilidades tiveram a maioria da avaliação concordando parcialmente, cerca de $46 \%$, com a percepção da existência das habilidades na execução das atividades de perícia contábil criminal federal.

\subsection{Discussão agregada dos resultados}

A pesquisa questionou os peritos e delegados da Polícia Federal sobre suas percepções em relação à relevância de algumas habilidades investigadas na literatura internacional e, em razão da experiência dos respondentes, foi possível aprofundar a pesquisa, por meio de questionamentos sobre a aplicação prática das mesmas habilidades, com a possibilidade de sugestões de outras habilidades não listadas na pesquisa. 
Discutir a importância das habilidades necessárias para o contador forense atuar na prática investigativa permitiu que os usuários e praticantes elencassem como atividades mais relevantes (Tabela 2), a "comunicação escrita", a "análise dedutiva" e o "pensamento crítico". O resultado possibilitou a comparação com a pesquisa de Digabriele (2008), em que foi observado um alinhamento dos resultados, porém divergiu com a pesquisa de Astutie e Utami (2013), já que nessa a flexibilidade técnica ficou como a mais importante.

Observou-se também que o pensamento crítico aparece entre as primeiras habilidades nas pesquisas internacionais, corroborando com a percepção dos praticantes quando o resultado é separado da percepção dos usuários, sendo que estes percebem o pensamento crítico como a quinta habilidade mais relevante. Essa divergência demonstra um distanciamento entre praticantes e usuários naquilo que é considerado essencial pelos peritos criminais contábeis no exercício do seu mister, a capacidade de decifrar a diferença entre opinião e fato.

No que tange à percepção das habilidades menos relevantes entre as investigadas, os peritos e delegados, tanto no resultado conjunto ou separado, elencaram a entrevista e a resolução e negociação de conflitos, essa constatação está alinhada com o resultado encontrado por Davis et al. (2010), já o conhecimento jurídico específico também apareceu entre as habilidades menos relevantes, convergindo com o trabalho de Digabriele (2008). Pode-se inferir que a habilidade "conhecimento jurídico específico" foi influenciada em razão de os usuários serem operadores do Direito, pois esse quesito não investiga a possibilidade de atuação jurídica do perito, mas a capacidade de compreender os procedimentos legais básicos e questões jurídicas, incluindo as regras de prova.

No que tange à entrevista e a resolução e negociação de conflitos, embora não seja comum o perito criminal contábil realizar o trabalho de campo, pois muitos dados necessários para a materialização de um crime são alcançáveis por meio de pesquisa de banco de dados, em decorrência dos avanços tecnológicos e registros eletrônicos contábeis e de transações financeiras, o contador forense não deve abrir mão de estar preparado para realização dessas habilidades, já que o uso pode ser necessário. Além do treinamento dos profissionais que já atuam no ramo, há a necessidade de se desenvolver cursos de contabilidade forense para atender uma demanda crescente de profissionais capacitados no combate à fraude. Na formação de currículos poderão ser usados os resultados das percepções da aplicação prática das habilidades, conforme Tabela 3, em que os peritos e delegados entenderam que estão mais presentes a comunicação escrita, a análise dedutiva e o pensamento crítico.

Os contadores forenses podem ser chamados para esclarecimento de suas conclusões, o que pode ser feito por escrito ou de forma verbal, e o comparecimento a um tribunal diante de júri, juízes, promotores e advogados, configura-se como uma situação de pressão. Nesse caso, uma das habilidades mais exigidas, além da "comunicação oral", é a "serenidade", habilidade considerada a sétima mais presente pelos praticantes, enquanto os delegados consideraram a segunda habilidade mais presente. Esse achado demonstra que os peritos estão sendo observados pelos usuários como profissionais capazes de manter a atitude calma em situações de pressão.

Materializar a prova de um crime não é das tarefas mais simples, para isso, faz-se necessário o desenvolvimento de diversas habilidades. Pensando nessa diversidade, foi solicitado aos respondentes que fizessem sugestões de habilidades não listadas e, com isso, foi possível capitar dezesseis habilidades, conforme a Tabela 9, sendo que as três mais lembradas foram a "proatividade", a "objetividade" e a "atualização". As perícias criminais contábeis são, na maioria das vezes, complexas e volumosas, o que faz pensar na necessidade de "proatividade" e "objetividade" para solução dos casos.

Quanto à análise dos componentes principais, foram encontrados grupos de habilidades com ênfase para o "desempenho técnico", "analítico" e "estratégico", em que os peritos apresentaram diferença de percepção em relação aos delegados. Quanto à percepção estratégica, conhecimento jurídico, investigativo e desempenho analítico, o resultado demonstra que os peritos perceberam de maneira mais positiva os grupos que são relevantes para construção e desenvolvimento das habilidades que podem fortalecer a contabilidade forense. Cabe ressaltar, ainda, a comparação dos componentes principais com a pesquisa de Digabriele (2008), em que não há alinhamento dos grupos encontrados quanto à importância das habilidades. 
Não obstante as limitações quanto aos demais usuários da perícia contábil criminal que não foram submetidos à pesquisa, esse estudo contribui para decisões que visem fortalecer as habilidades dos peritos criminais, por meio de treinamentos e capacitações, bem como para formação de currículos para novos cursos universitários em nível de graduação e pós-graduação de contabilidade forense.

\section{Conclusão}

Com base em pesquisas internacionais, foram identificas habilidades consideradas relevantes para o exercício da contabilidade forense, e quando submetidas à percepção dos peritos criminais contábeis e delegados da polícia federal, ficou constatado que há um alinhamento dos resultados encontrados, sendo as habilidades "pensamento crítico", "comunicação escrita" e "análise dedutiva", consideradas as mais relevantes. É necessária uma discussão no País sobre a formação e preparação desse profissional com a demanda crescente e que está diretamente envolvido na solução de crimes financeiros de grande repercussão, bem como é necessário estimular produções científicas em relação ao tema. Mesmo as discussões e produções sendo incipientes, não houve prejuízo em relação à percepção das habilidades relevantes identificadas pelos praticantes e usuários nacionais em comparação com os resultados internacionais.

Os peritos entendem que, para uma contribuição eficaz para persecução penal, é fundamental a habilidade "pensamento crítico", ou seja, a capacidade de diferenciar a opinião do que é fato na realização de uma perícia contábil criminal, assim como a "comunicação escrita" faz toda diferença na produção do laudo. Habilidades relacionadas com o trabalho de campo, como as entrevistas e a resolução e a negociação de conflitos, não foram consideradas relevantes entre as investigadas.

Faz-se necessário um melhor esclarecimento aos usuários e a sociedade sobre o que é e o que faz a perícia contábil criminal, haja vista a habilidade "conhecimento jurídico específico" ter ficado também entre as menos relevantes, porém é inimaginável um competente contador forense sem a capacidade de compreender os procedimentos legais básicos e questões jurídicas, incluindo as regras de provas. Cabe ressaltar que os próprios experts não consideraram essa habilidade entre as mais relevantes, o que parece contraditório. Aproveitar a experiência dos respondentes se mostrou positivo, pois além de terem sido mais críticos na percepção da aplicação prática das habilidades, puderam sugerir habilidades não listadas, com isso a "proatividade", a "objetividade" e a "atualização" foram as três mais lembradas.

Os resultados obtidos contribuem para o aperfeiçoamento dos profissionais que já atuam na área, assim como para diretrizes de treinamentos, novos cursos de graduação e pós-graduação, na estruturação de currículos para formação de novos contadores forenses, pois se verificou que não é somente o conhecimento de como as coisas devem ser feitas, o contador forense deve desenvolver bem a solução de "problemas não estruturados", "habilidades investigativas", "flexibilidades técnicas", entre outras habilidades que não fazem parte dos currículos atuais. Por fim, verifica-se que as habilidades investigadas e sugeridas contribuem para todas as áreas da perícia contábil.

Considerando que o estudo capitou a percepção prática das habilidades e também sugestões dos respondentes, poderão ser realizadas pesquisas futuras visando complementar o constatado até aqui e aprofundar o resultado das percepções práticas e das habilidades sugeridas pelos respondentes. 


\section{Referências}

Astutie, Y. P. \& Utami, Y. (2013,). Characteristics and Relevant Skills of The Forensic Accountant: An Empirical Study on Indonesia. In International Conference on Accounting and Finance (AT). Proceedings (p. 122). Global Science and Technology Forum. DOI:10.5176/2251-1997_AF13.44

Bardin, L. (1979). Análise de conteúdo. Lisboa: Edições 70.

Bhasin, M. (2013). An Empirical Investigation of the Relevant Skills of Forensic Accountants: experience of a Developing Economy. European Journal of Accounting Auditing and Finance Research, 1(2), pp. 11-52. DOI: 3200/JOEB.83.6.331-338

Black, H.C. (1971). Black's Law Dictionary. West Publishing CO. Recuperado em 30 julho, 2015, de http:// www.nationallibertyalliance.org/files/docs/Books/Black's\%20Law\%204th\%20edition,\%201891.pdf

Boys, J. (2008). Forensic Accounting in New Zealand: exploring the gap between education and practice. New Zealand: Auckland University.

Bracarense, P. A. (2012). Estatística Aplicada às Ciências Sociais (1 ed.). Curitiba: IESDE Brasil S.A.

Conselho Federal De Contabilidade. Norma Brasileira de Contabilidade - NBC TP 01. Dá nova redação à NBC TP 01 - Perícia Contábil. Recuperado em 27 fevereiro, 2015, de https://cfc.org.br/wp-content/uploads/2016/02/NBC_TP_01.pdf

Crumbley, D. L., Hitger, L.E. \& Smith, G. S. (2013). Forensic and Investigative Accounting. Wolters Kluwer (6 ed.).

Davis, C., Farrell, R. \& Ogilby, S. (2010). Characteristics and skills of the Forensic Accountant. American Institute of Certified Public Accountants.

Digabriele, J. A. (2008). An empirical investigation of the relevant skills of forensic accountants. Journal of Education for Business, 83(6), pp. 331-338. DOI:10.3200/JOEB.83.6.331-338

Freitas, H., Oliveira, M., Saccol, A. Z. \& Moscarola, J. (2000). O método de pesquisa survey. Revista de Administração da Universidade de São Paulo, 35(3), pp. 105-112.

Harris, C. K. \& Brown, A. M. (2000). The qualities of a forensic accountant. Pennsylvania CPA Journal, 71(1), pp. 2-3.

Humphrey, C., Moizer, P. \& Turley, S. (1993). The audit expectations gap in Britain: An empirical investigation. Accounting and Business Research, 23(sup1), pp. 395-411. DOI:10.1080/00014788.1993.9 729907

Lakatos, E. M., \& Marconi, M.A. (2003). Metodologia Científica (2 ed.). São Paulo: Atlas.

Oliveira, A.B.S. (2011). Métodos da Pesquisa Contábil. São Paulo: Atlas.

Oliveira, A.T. (2002). Proposta Metodológica de Perícia Contábil para o Crime de Apropriação Indébita Previdenciária.

Peleias, I. R. (org.). (2006). Didática do Ensino da Contabilidade. São Paulo: Saraiva.

Silva, L. M. (2012). Contabilidade Forense: princípios e fundamento. São Paulo: atlas.

Silva, R. M. (2012). Contabilidade Forense no Brasil: uma proposição de metodologia. Dissertação. Universidade Presbiteriana Mackenzie, São Paulo.

Skalak, S.L., Golden, T., Clayton, M. \& Pill, J. (2011). A Guide to Forensic Accounting Investigation (2 ed.). New Jersey: John Wiley \& Sons.

West Virginia University (2007). Education and Training in Fraud and Forensic Accounting: A Guide for Educational Institutions, Stakeholder Organizations, Faculty, and Students. 


\section{Apêndice A - Questionário}

Questionário sobre a percepção dos peritos criminais contábeis federais e dos delegados da Polícia Federal em relação às competências necessárias para realização das perícias contábeis criminais da Polícia Federal à luz do conceito de contabilidade forense (contabilidade forense) pesquisado na literatura Norte- Americana.

Perito criminal federal

Qual sua faixa etária?
Delegado de Polícia Federal

Lotação:
31-40 anos
$\square 41$ a 50 anos
20-30 anos

口mação?

Qual seu nível de formação?

Bachare

$\square$ Especialista

Mestre

Doutor

Ph.D.

Qual sua área de formação? Principal e outras.
Contabilidade
Economia
$\square$ Direito
Outra (especifique)

Qual seu tempo de experiência como delegado ou perito?
0 a 5 anos
6 a 10 anos
11 a 15 anos
16 a 20 anos

A seguir avalie a importância das habilidades abaixo com atribuição de nota de 1 a 6 , sendo:

\begin{tabular}{cccccc}
\hline (1) & $(2)$ & $(3)$ & $(4)$ & (5) & (6) \\
\hline Não se aplica & Discordo & $\begin{array}{c}\text { Discordo } \\
\text { parcialmente }\end{array}$ & Neutro & $\begin{array}{c}\text { Concordo } \\
\text { parcialmente }\end{array}$ & Concordo \\
\hline
\end{tabular}

\begin{tabular}{|c|c|c|c|c|c|c|}
\hline Parte 1 - Quesitos sobre a importância das habilidades abaixo para perícia contábil & 1 & 2 & 3 & 4 & 5 & 6 \\
\hline $\begin{array}{l}\text { 1. Análise dedutiva - habilidade de focar em contradições financeiras que não se } \\
\text { enquadram no padrão normal de uma tarefa. }\end{array}$ & & & & & & \\
\hline 2. Pensamento crítico - capacidade de decifrar a diferença entre opinião e o fato. & & & & & & \\
\hline $\begin{array}{l}\text { 3. Resolução de problemas não estruturados - capacidade de abordar cada situação } \\
\text { (única) e se trata preparado para resolver problemas com abordagem não estruturada. }\end{array}$ & & & & & & \\
\hline $\begin{array}{l}\text { 4.Flexibilidade Técnica - capacidade de afastar-se de procedimentos padronizados e } \\
\text { examinar cuidadosamente as situações pelos sinais de alertas atípicos. }\end{array}$ & & & & & & \\
\hline $\begin{array}{l}\text { 5. Proficiência analítica - capacidade de examinar o que deve ser fornecido em vez do que } \\
\text { é fornecido (análise de viabilidade). }\end{array}$ & & & & & & \\
\hline $\begin{array}{l}\text { 6. Comunicação oral - capacidade de comunicar de forma eficaz no discurso por meio de } \\
\text { depoimento de um especialista e explicação geral das bases de opinião. }\end{array}$ & & & & & & \\
\hline $\begin{array}{l}\text { 7. Comunicação escrita - capacidade de comunicar de forma eficaz, por escrito, por meio } \\
\text { de relatórios, tabelas, gráficos e as bases da opinião. }\end{array}$ & & & & & & \\
\hline $\begin{array}{l}\text { 8. Conhecimento jurídico específico - capacidade de compreender os procedimentos } \\
\text { legais básicos e questões jurídicas, incluindo as regras de provas. }\end{array}$ & & & & & & \\
\hline 9. Serenidade - capacidade de manter uma atitude calma em situações de pressão. & & & & & & \\
\hline $\begin{array}{l}\text { 10. Rastreamento de ativos - capacidade de identificar bens ou valores ocultos ou } \\
\text { dissimulados. }\end{array}$ & & & & & & \\
\hline 11. Habilidade de entrevista - capacidade de obter testemunho pessoal. & & & & & & \\
\hline $\begin{array}{l}\text { 12. Habilidade investigativa - capacidade de possuir alto nível de atitude questionadora. } \\
\text { Se dispor a investigar opiniões e/ou fatos que podem sugerir fraude. }\end{array}$ & & & & & & \\
\hline 13. Resolução e negociação de conflitos - capacidade de solucionar controvérsias. & & & & & & \\
\hline
\end{tabular}




\begin{tabular}{|c|c|c|c|c|c|c|}
\hline Quesitos quanto à existência das habilidades na perícia contábil criminal federal & 1 & 2 & 3 & 4 & 5 & 6 \\
\hline $\begin{array}{l}\text { 14. Os peritos criminais contábeis federais possuem a habilidade de ANÁLISE DEDUTIVA? } \\
\text { Capacidade de focar em contradições financeiras que não se enquadram no padrão normal de } \\
\text { uma tarefa. }\end{array}$ & & & & & & \\
\hline $\begin{array}{l}\text { 15. Os peritos criminais contábeis federais possuem a habilidade de PENSAMENTO CRÍTICO? } \\
\text { Capacidade de decifrar a diferença entre opinião e o fato. }\end{array}$ & & & & & & \\
\hline $\begin{array}{l}\text { 16. Os peritos criminais contábeis federais possuem a habilidade de RESOLUÇÃO DE } \\
\text { PROBLEMAS NÃO ESTRUTURADOS? Capacidade de abordar cada situação (única) e preparado } \\
\text { para resolver problemas com abordagem não estruturada. }\end{array}$ & & & & & & \\
\hline $\begin{array}{l}17 \text { Os peritos criminais contábeis federais possuem a habilidade de FLEXIBILIDADE TÉCNICA? } \\
\text { Capacidade de afastar-se de procedimentos de auditoria padronizados e examinar } \\
\text { cuidadosamente as situações pelos sinais de alertas atípicos. }\end{array}$ & & & & & & \\
\hline $\begin{array}{l}18 \text { Os peritos criminais contábeis federais possuem a habilidade de PROFICIÊNCIA ANALÍTICA? } \\
\text { Capacidade de examinar o que deve ser fornecido ao invés do que é fornecido (análise de } \\
\text { viabilidade). }\end{array}$ & & & & & & \\
\hline $\begin{array}{l}\text { 19. Os peritos criminais contábeis federais possuem a habilidade de COMUNICAÇÃO ORAL? } \\
\text { Comunicar de forma eficaz no discurso via depoimento de um especialista e explicação geral das } \\
\text { bases de opinaão. }\end{array}$ & & & & & & \\
\hline $\begin{array}{l}\text { 20. Os peritos criminais contábeis federais possuem a habilidade de COMUNICAÇÃO ESCRITA? } \\
\text { Capacidade de comunicar de forma eficaz, por escrito, por meio de relatórios, tabelas, gráficos e } \\
\text { as bases da opinião. }\end{array}$ & & & & & & \\
\hline $\begin{array}{l}\text { 21. Os peritos criminais contábeis federais possuem a habilidade de CONHECIMENTO JURÍDICO } \\
\text { ESPECÍFICO? Capacidade de compreender os processos legais básicos e questões jurídicas, } \\
\text { incluindo as regras de provas. }\end{array}$ & & & & & & \\
\hline $\begin{array}{l}\text { 22. Os peritos criminais contábeis federais possuem a habilidade de SERENIDADE? Capacidade } \\
\text { de manter uma atitude calma em situações de pressão. }\end{array}$ & & & & & & \\
\hline $\begin{array}{l}\text { 23. Os peritos criminais contábeis federais possuem a habilidade de RASTREAR ATIVOS? } \\
\text { Capacidade de identificar bens ou valores ocultos ou dissimulados. }\end{array}$ & & & & & & \\
\hline $\begin{array}{l}\text { 24. Os peritos criminais contábeis federais possuem habilidade de ENTREVISTA? Capacidade de } \\
\text { obter testemunho pessoal. }\end{array}$ & & & & & & \\
\hline $\begin{array}{l}\text { 25. Os peritos criminais contábeis federais possuem habilidade INVESTIGATIVA? - Capacidade } \\
\text { de possuir alto nível de atitude questionadora. Se dispor a investigar opiniões e/ou fatos que } \\
\text { podem sugerir fraude. }\end{array}$ & & & & & & \\
\hline $\begin{array}{l}\text { 26. Os peritos criminais contábeis federais possuem habilidade de RESOLUÇÃO E NEGOCIAÇÃO } \\
\text { DE CONFLITOS? Capacidade de solucionar controvérsias. }\end{array}$ & & & & & & \\
\hline
\end{tabular}

27. Informe três habilidades não listadas acima e que você entende como importantes para desenvolver a atividade de perícia contábil criminal federal? Especifique.

28. Os peritos criminais contábeis federais possuem a(s) habilidade(s) sugeridas por você? 